\title{
Os anos tardios de Ernesto De Fiori no Brasil
}

\author{
WALTER ZANINI
}

$\mathrm{P}$ OR RAZOESS POIÍTICAS, por preconceitos e perseguições raciais ou em conseqüência da Segunda Guerra Mundial, o Brasil tornou-se um dos países do Novo Mundo que maior número de artistas refugiados europeus absorveu nos decênios de 1930-40. Embora essa demanda não pudesse evidentemente se comparar à que ocorreu nos Estados Unidos, foram muitos os que tomaram o seu rumo para escapar às condições insuportáveis de vida e ao conflito bélico. No significativo aspecto quantitativo dessa imigração, envolvendo algumas dezenas de indivíduos, nota-se a presença de nomes de verdadeira importância no contexto da arte moderna, como são os de Ernesto de Fiori, Bernard Rudofsky, August Zamoyski, Arpad Szenes e Maria Helena Vieira da Silva. Foi ainda apreciável a parcela de arquitetos que tiveram a mesma opção, o que observamos também na literatura, como nos casos de Stefan Zweig e Georges Bernanos, ou na música, com H.J. Koellreutter, para não citar senão alguns dos nomes mais conhecidos.

Ao abordarmos essa questão específica relacionada às contingências de uma trágica situação internacional é esclarecedor lembrar, mesmo se de passagem, que o Brasil possui forte tradição receptiva a artistas europeus. Com efeito, a história revela a atração que o país exerceu, no século XIX, em numerosos pintores, escultores e desenhistas, além de arquitetos, não raros dos quais aqui definitivamente fixados, paralelos podendo ser estabelecidos a respeito com outras nações da América do Sul. As grandes levas migratórias dirigidas para o Brasil, a partir dos três últimos decênios do Oitocentos, fortaleceriam ainda mais essa tendência. Tal fato, que diz respeito a artistas em diversificados níveis, é dos mais relevantes nos estados do Sul e mais ainda em São Paulo, cidade que constituiu o principal pólo de atração de imigração, sobretudo a italiana. $O$ Rio de Janeiro mantinha, entretanto, o seu histórico fascínio sobre os artistas europeus, como se constata pela existência nos anos de 1920-30 de um núcleo de pintores de origem germânica, arraigados ao expressionismo (Burlamaqui, 1984). Vale notar, por outro lado, que o fenômeno da imigração japonesa, no começo do século $\mathrm{xx}$, produziu efeitos culturais permanentes, formando-se na capital paulista uma comunidade de artistas de orientação moderna, incluindo descendentes.

O movimento modernista brasileiro, fundado entre o fim dos anos 10 e o começo do decênio de 20 , contou, como sabemos, com a participação de artistas 
do Velho Mundo, entre os quais o lituano Lasar Segall, membro do expressionismo alemão, por muitos anos ativo em Dresde e que, chegado em 1923, veio a se tornar um dos principais desses imigrados, cumprindo destacado papel no processo de renovação artística local.

Foi ao desenrolar-se a segunda e última etapa desse movimento, (décadas de 20 e 30 ), quando as concepções de dominante ordem formal cediam bastante à adoção de conteúdos ideológicos - disseminados também em outros centros das Américas - e no diapasão do evento que foi a Revolução política e social de 1930 no Brasil - que ocorreu nova e importante radicação, temporária ou definitiva, de artistas imigrantes. Já aludimos à convergência motivada pela guerra: o segundo conflito mundial foi a causa essencial da escolha do Rio por parte de cerca de 20 deles, de diferentes nacionalidades européias, além de norte-americanos e japoneses. Malgrado a instabilidade da situação e o vazio de perspectivas pesassem nos ânimos, desenvolveram esses artistas um trabalho que além de diferentes tipos de repercussão em sua obra foram fatores de influência no meio. Lembramos a este último propósito os casos de Maria Helena Vieira da Silva e de Arpad Szenes que criaram em torno de si, em sete anos de estada, entre 1940-47, ambiente dos mais estimulantes do qual participaram jovens e destacados artistas, poetas e críticos.

Entretanto, é na deslocação de Ernesto de Fiori (1884-1945), da Alemanha para o Brasil, aos 51 anos, que desejamos concentrar nossa atenção, no momento em que transcorre o $50^{\circ}$ aniversário de sua morte, nesta capital, data que não podemos deixar passar em branco. O clima político, a censura e a perseguição à criação artística imposta pelo nazismo na década de 30 haviam tornado intolerável a permanência desse grande escultor ítalo-alemão em Berlim. Essa repulsa ao regime se constata também, é claro, em muitos outros artistas. Ao partir para visitar a família em São Paulo, em 1936, não podia ele supor, no entanto, que em sua vida de muitas experiências migratórias essa viagem fosse ter o destino de um exílio definitivo (1). Por essa razão, a prolongada estada que o esperava e que só terminaria com o seu falecimento, em 1945, não se fez sem traumas. O inesperado meio a que as circunstâncias o conduziram, porém, não o desencorajou de ainda prosseguir com sua obra de escultor de real renome internacional e, fato surpreendente, de retomar largamente a sua antiga e reprimida paixão pela pintura.

Ao chegar para a breve temporada que tinha em mente - "de recreio" como declarou (Correio de S.Paulo, 1936), trazendo na bagagem tão somente objetos de primeira necessidade, despertou desde logo a atenção de nossos intelectuais e artistas, alguns dos quais membros do movimento modernista, como os escritores Mário de Andrade e Sérgio Milliet (que escreveriam sobre ele), o poeta, escritor e jornalista Menotti del Picchia e o pintor e animador cultural Paulo Rossi Osir. 
De Fiori, contudo, em que pese a aura européia da cidade, de início não gostou de São Paulo, registrando esse desagrado no artigo Die Lange Fabrt, publicado em 1936 (2). Por outro lado, não detestou menos o meio artístico do Rio de Janeiro, por ocasião de curta passagem. Procurou, porém, ter uma idéia do interior do país, viajando pelo rio Paraná. O apoio da família e a encomenda de retratos esculpidos asseguravam-lhe a sobrevivência que, todavia, nunca the deve ter sido muito fácil na permanência que se estendia para além de suas previsões. O nazismo, a que seus princípios liberais se opunham radicalmente (como, aliás, o comunismo), e o agravamento da situação política européia impediam seu regresso, mais adiante definitivamente comprometido pela guerra. A distância geográfica, entretanto, não foi razão para que se mantivesse como cidadão inerte diante dos acontecimentos. Assim que o Brasil rompeu sua neutralidade, em 1942, De Fiori publicou artigos veementes contra a ditadura alemã e a favor da paz (3).

No seu inconformismo procurou fundar a que seria a liga denominada Resistência Espiritual contra o Nazismo (para a qual adotou como lema a palavra Rech, inscrita numa espada) e, episódio curioso, tentou causar intrigas entre Goering e Hitler através da sobrinha do marechal, consulesa da Alemanha em São Paulo. Quando do afundamento de navios brasileiros por submarinos no Atlântico, redigiu manifesto conclamando alemães e italianos residente no Brasil a protestarem contra esses ataques e, mais do que isso, planejou mecanismos antitorpedos, cujos desenhos chegou a oferecer ao governo dos Estados Unidos. Mas não alcançou êxito em quaisquer dessas intenções.

Não obstante fosse uma personalidade notoriamente reservada e passasse por um momento psicológico difícil, De Fiori procurou entrosar-se ao meio, não lhe faltando desde logo alguns relacionamentos que se converteram em amizades profundas, como as que o ligaram a Sérgio Milliet e Paulo Rossi Osir. Não demorou para realizar mostras individuais, participando também de coletivas e salões. Expôs no inovador Salão de Maio e ingressou na Familia Artística Paulista, associação de artistas preocupados com a qualidade do métier, sendo um elevado exemplo profissional não apenas por sua excelência escultórica mas, também, pela liberdade de expressão que mostrava em pintura. Trouxe ainda préstimos através de seus fundamentados artigos sobre arte (4). Abordaremos adiante a sua malograda experiência como escultor no Rio de Janeiro. É interessante lembrar ainda que não descurou de sua antiga e épica paixão pelo iatismo (5).

A produção de De Fiori no Brasil - que em grande parte pudemos levantar para a exposição retrospectiva realizada no MAC-USP, em 1975, com a catalogação de 71 esculturas, 173 pinturas e 238 desenhos, afora algumas litografias e azulejos (MAC-USP, 1975, n. 11:134) - compreendeu dois tempos distintos: o primeiro, de prevalência da escultura, entre 1936 e 1939 e o segundo, de 1940 a 1945, em que reduziu essa atividade para concentrar-se na pintura. Por sua vez, o desenhista, de não menor nível, mostrou-se bem mais operante no período 
de maior intensidade do pintor, guardando em rẹlação a este como ao escultor manifesta autonomia.

Seu trabalho escultórico incluiu principalmente retratos, perfazendo 49 obras (segundo o levantamento parcial aludido e que dá idéia do quanto era solicitado), seguindo-se uma série de 12 figuras femininas, além de número menor de figuras masculinas e um relevo. Elaborados no gesso ou em bronze e bem mais raramente em terracota, essas esculturas são de pequeno formato (a maior tem 121 centímetros de altura), como as que dominam as fases anteriores de sua carreira. Em sua maior parte, pertencem ainda hoje a coleções públicas e particulares de São Paulo.

A escultura de De Fiori, no Brasil, é seqüencial à que produzira nos últimos anos de residência em Berlim, não faltando quem se pergunte sobre o nível dessa continuidade num ambiente cultural sem a mesma densidade. No retratogênero na época contemporânea em perda de prestígio mas a que ele soubera trazer uma vibração anímica própria, indo a fundo na individualidade dos modelos, o que escasseava na intemporalidade de Despiau e de raros paralelos na escultura moderna -, nem sempre alcançou os níveis desejados nas encomendas que atendia. Entre os seus melhores exemplos, incluiríamos os retratos de Giuseppe Ungaretti, de sua sobrinha Giuliana Heins de Fiori, da artista Moussia Pinto Alves, todos de 1936 e o da senhora Ivone Arié Levi, de 1941. A densidade do elemento introspectivo dos retratados tornou-se maior na evolução de sua obra. Por sua vez, o antigo culto pela figura feminina jovem possibilitou-lhe nova e valiosa série de nus situados numa convergência gótico-clássica. Elas posam em suas variantes de gestos simples e naturais, contrabalançando a profundidade meditativa e a sensualidade. Contrastam na sua estaticidade com três figuras masculinas que executou: Homem em marcha, de 1937, Guerreiro, de 1938 e o alto relevo de um homem andando que acena para trás com o braço direito erguido, do mesmo ano, o qual se reporta a tema similar de c. 1930. A extroversão dessas figuras em movimento, traduzindo mais abertamente a complexidade da etapa que o artista atravessava, de uma textura sempre das mais aceradas, avizinhava-se do simbólico Der Fliehender, de 1936, deixado no atelier de Berlim.

O ambiente artístico de São Paulo contava com poucos escultores modernos nos anos de 1930-40, sobressaindo-se os nomes de Victor Brecheret e Bruno Giorgi. Este último era um desses raros valores novos, iniciado com Maillol, em Paris, e bastante relacionado a De Fiori ao regressar ao Brasil. A forte ascendência do artista ítalo-alemão representava uma fonte segura de influência ou estímulo no meio restrito, como veremos também em termos de pintura. Recorde-se, contudo, que na cidade que o hospedava não se ofereceria oportunidade alguma para a realização de obras públicas. Em verdade, nos anos de recessão econômica de 1930, nada havia entre nós que pudesse ser comparado ao projeto de fomento 
às artes da Works Progress Administration (WPA), nos Estados Unidos ou às medidas postas em prática, nos anos 20 , pelo governo revolucionário do México.

Entretanto, quando da construção da nova sede do Ministério da Educação, no Rio de Janeiro, De Fiori, a exemplo de outros escultores, foi convidado a apresentar uma série de maquetas com vistas ao programa de integração das artes originariamente previsto por Le Corbusier, arquiteto consultor. Mário de Andrade deve ter contribuído para que lhe fosse feito o convite. Transferindo-se temporariamente para a então capital da República, em 1938, De Fiori, seguindo livremente o ideário iconográfico proposto, modelou várias versões de três figuras: O Brasileiro, Maternidade e Mulher Reclinada, para as quais previam-se locações distintas, dentro e fora do edificio. Trabalhou com esmero nesse conjunto de imagens de superfícies convulsas, cuja percepção afastava-se da estatuária despojada de seus primeiros tempos na Europa. No caso de O Brasileiro, ele definiu com segurança certos elementos antropológicos genéricos, à distância de qualquer referência mais realista e imune a apelos retóricos.

O que realizou, no entanto, não agradou aos arquitetos, em cujas mãos concentrava-se toda a responsabilidade do programa. Lúcio Costa reconheceu em Ernesto de Fiori "um escultor de primeira qualidade, de grande vitalidade e extremamente apurado", porém seu julgamento era de que faltavam às obras o "sentido arquitetônico e monumental que interessava ao Ministério". Criticou ainda o individualismo do artista (MAC-USP, 1975, n.25:19). Por outras palavras, além da conjectural falta de monumentalidade, as figuras não se amoldariam aos perfis puros e suaves do edificio que se tornou marco da arquitetura moderna brasileira. É de recordar-se o que afirmou um dos principais críticos do artista no país, Wolfgang Pfeiffer (1961), sobre o fato apontado, de as figuras mostrarem-se como que "voltadas para dentro". O historiador enfatizou seus muitos predicados mas concluiu que não possuíam a mesma "comunicabilidade" da Inglesa ou da Mof́a em Pé, realizadas em Berlim. Seja como for, a qualidade diferenciada da fase vivida pelo artista, incapaz de concessões, apelava para uma consideração. Mas surgiram inevitáveis incompatibilidades no Ministério e a recusa acabou por consumar-se. Algum tempo depois De Fiori publicou o artigo Os Monumentos (1941), reafirmando o seu conhecido pensamento sobre o papel da escultura, "que não significa nada, ou melhor, significa escultura", e que deve recusar-se "a transmitir outra coisa que não sejam sentimentos de caráter bastante geral". Considerou nesse texto a quase totalidade "dos monumentos destes últimos sessenta anos ou mais como um capítulo triste da história da arte"

Inicialmente realizada de permeio ao trabalho escultórico, a pintura, a partir de 1940, passou a ser prioritária para De Fiori. São sabidos os seus inícios de pintor em Munique, em 1903, o encontro com o influente Hodler, em Roma, em 1904, assim como o dramático episódio de sua depressão moral em Paris, em 
1911, quando chegou a pensar em abandonar a arte, desencorajando-se diante da obra de Cézanne. Se a ela retornou em seguida, o foi pela via da escultura através do ensinamento junto a Hermann Haller. A inclinação pictórica, todavia, não se desvaneceu jamais em seu espírito, subsistindo inclusive adstrita à evolução do escultor. Scheffler (1920) e Siemsen (1929) referiram-se às suas atividades específicas de pintor.

Seria, porém, nos anos mais tardios, vivendo a experiência brasileira e sofrendo a impossibilidade de voltar a Berlim mas "logo capturado" pelo novo meio - como testemunhou Bernard Rudofsky (1939), refugiado, seu contemporâneo em São Paulo - que De Fiori pode dar vazão ao seu impulso poético primeiro. É sobretudo a pintura que lhe permitirá integrar-se à "nova realidade cultural", como observou Luís Martins (1945). O pintor, todavia, jamais seria tributário do escultor, mesmo se considerada a tendência a afirmar o desenho independentemente da cor.

Embora a evolução demonstrada em escultura, foi na pintura que De Fiori encontrou caminho mais livre para a expressão de suas cargas emotivas e a possibilidade de criação em nível de exclusiva obrigação interior. Como afirma Sérgio Milliet (1959), "a pintura exprimia o romantismo do artista, esse romantismo que o domínio do barro sabe requintar e velar". Para o crítico, De Fiori era "um indivíduo de inteligência brilhante e paradoxal" com "horror à disciplina estrita que esquematiza e padroniza a humanidade". Acompanhando-o no atelier, apercebera-se de seu processo de trabalho, na busca de "libertar as emoções". Afirma ainda: "Em sua pintura e em seu desenho somente a expressão contava. E a expressão imediata (Milliet, 1959). Acreditava, porém, que De Fiori pintava para se distrair da escultura, quando, em verdade, em seus últimos anos, a pintura se tornara, para ele, imposição vital. Era um desafio que enfrentava com a determinação que lhe faltara no passado, abrindo-se a uma figuratividade expressionista da maior liberdade.

De Fiori desenvolveu uma série de temas em sua pintura. Sensibilizado pela natureza, voltou-se para a paisagem do oeste do estado de São Paulo e logo para a paisagem urbana da capital e sua represa. Abordou a figura humana, polarizando-a em três linhas iconográficas principais: uma, de fundamentos simbólicos, em que representa São Jorge contra o Dragão, além de míticas cenas de batalha e lutas de cavaleiros; outra consagrada a Arlequim e, finalmente, uma terceira, na qual sucedem-se indivíduos isolados ou grupos que geralmente participam de pequenos acontecimentos da vida mundana. Outro de seus interesses foi a natureza-morta.

Resultado do seu encontro com a região de terra roxa de São Paulo, as paisagens de Ernesto de Fiori são pintadas de memória e têm como motivo cenas de mata, fazendas, margens de rio e ainda terrenos calcinados, ou seja, incendiados, 
cuja dramaticidade transportou para os seus quadros. Diversamente da serenidade que revelara em sua pintura do começo do século, nessas obras o desenho é irrompido, a paleta de meios tons alterna luz e sombreados densos e a pincelada é visível em seu rastro ríspido.

Além do ambiente rural, a cidade de São Paulo - que descreveu como "uma grande e inacabada cidade", com aspecto de "uma Babel" (De Fiori, 1936) - foi por ele tratada na agitação característica de suas ruas. No entanto, é a grande mancha d'água de Santo Amaro - a qual certamente lhe avivava a lembrança dos grandes lagos em torno de Berlim - que se tornou um de seus temas favoritos (recordando-se que ele era um campeão de iatismo). Em telas a óleo e em guache, De Fiori representou as águas revoltas da represa e seus barcos a vela sob céus borrascosos, utilizando traços impetuosos de pincel e a fineza de suas cores transparentes.

A pintura de paisagens, como as marinhas de De Fiori, que se colocam na tradição do expressionismo, revela correspondências com a direção realistaexpressionista de um grupo de pintores locais e, ainda, influências que neles exerceu pela liberdade dada à presença alternada de desenho e cor. A incidência de De Fiori surgiu explicitamente em membros do Grupo Santa Helena, facção de artistas que integravam a Família Artística Paulista, como Alfredo Volpi e Mário Zanini, mas teve repercussões mais amplas, "enquanto espírito e técnica", como reconhecem vários artistas (MAC-USP, n. 11:24).

Um clima não menos empenhado e extroverso reveste a figura do Arlequim, suas muitas representações simbólicas de São Jorge e o Dragão, significando a luta entre o bem e o mal, tema recorrente, assim como o das batalhas e cavaleiros em luta, constantes nos anos de 1940-42, que são metáforas da guerra em curso (sobre a causa contra o nazismo ele desenvolveu desenhos e litografias caricaturais). Proliferaram as cenas com figuras que posam a sós (podendo-se aí ver analogias com o hábito originário do atelier do escultor) ou de casais e grupos reunidos em encontros íntimos, em círculos sofisticados de certa burguesia paulistana. Sem dúvida, próximo ao espírito da Neue Sachlichkeit, o artista transmitiu aguçado retrato psicológico desse meio que freqüentava.

Essa iconografia, bastante voltada para a figura feminina jovem - a exemplo de sua escultura de várias épocas - é arrebatada, interessada em situações fugazes e como se captada por um flash fotográfico. Ela envolve personagens em clima de adversidade e com certeza possui implicações autobiográficas. Recorre o artista por vezes à ironia e ao sarcasmo, como no quadro Os Visitantes, de 1943, retratando um grupo que marcha com seus cães diante de uma mesa de jantar. Mas não era do feitio de De Fiori explorar os extremos que outros pintores históricos da Nova Objetividade haviam demonstrado. 
O espírito de liberdade que revela em seus golpes de pincel, sua composição solta, o não acabado não só de detalhes mas por vezes de trechos inteiros do quadro, as experiências com a simulação real do movimento (menos aceitáveis), os escorrimentos de tinta, os arrependimentos que deixa provocadoramente a descoberto, toda a expansão lírica do desenho rápido e das cores exuberantes que cobrem mesmo as largas molduras - tudo em suma o que serve às suas representações de grande inquietude, constitui uma contribuição específica e ponderável à poética visual expressionista.

Reconhecido no Brasil pela obra produzida e pela contribuição que trouxe a aspectos de nossa arte moderna durante um decênio de atividades em escultura, pintura e desenho, impõe-se, embora já tão tardiamente, a necessidade crítica, em termos internacionais, de reunir o que tem permanecido seccionado na apreciação da trajetória de Ernesto de Fiori (especialmente a pintura) e romper, portanto, a marginalização do que aqui realizou e que não foi pouco.

Notas

1 De Fiori viajou para o Brasil para visitar sua mãe, Maria Unger de Fiori e seu irmão mais velho, o médico Mário de Fiori, residentes em São Paulo. Desembarcou em Santos no início de agosto de 1936.

2 In: Deustsche Allgemeine Zeitung, n. 442, 20 set. 1936.

3 A exemplo de Tomada de posição. O Estado de S.Paulo, 25 mar 1942 e Paradermarsch, $O$ Estado de S.Paulo, 10 maio 1942.

4 De Fiori publicou artigos nos jornais $O$ Estado de S.Paulo, Fanfulla e Deutsche Zeitung, estes últimos das colônias italiana e alemã de São Paulo. De outro lado, enviou escritos à imprensa alemã, sobretudo ao Deutsche Allgemeine Zeitung. Lúcidos e de estilo incisivo, eles tratam de suas impressões sobre o Brasil, de eventos correntes, de arte e de política. Deixou numerosos manuscritos conservados por sua família em São Paulo.

5 Com grande experiência nesse esporte, De Fiori contribuiu fundamentalmente para o seu desenvolvimento no Brasil.

Referências bibliográficas

BURLAMAQUI, Maria Cristina. O Salão de 31 uma reavaliação. In: Lúcia Gouvêa Vieira, Salon de 1931, marco da revelação da arte moderna em nivel nacional. Rio de Janeiro 1984 , p. 40.

CORREIO DE S. PAULO. Um grande escultor moderno em São Paulo, 20 nov. 1936, p. 8. 
DE FIORI, Ernesto. Die Lange Fahrt. In: Deustsche Allgemeine Zeitung, n. 442, 20 set. 1936.

DE FIORI, Ernesto. Os Monumentos. O Estado de S.Paulo, 30 nov. 1941.

MAC-USP. Ernesto de Fiori (1884-1945) (catálogo). São Paulo, Museu de Arte Contemporânea da USP, 1975.

MARTINS, Luís. A Pintura de Ernesto de Fiori. In: São Paulo, Diário da Noite, 5 dez. 1945.

MILliET, Sérgio. De Fiori, Pintor e Desenhista (catálogo). São Paulo, Museu de Arte Moderna de São Paulo, set. 1959.

PFEIFFER, Wolfgang. Esculturase Desenhos - De Fiori. São Paulo, Galeria São Luís, set. 1961.

RUDOFSKY, Bernard. Exposição Ernesto de Fiori (catálogo). São Paulo, Casa e Jardim, 1939.

SCHEFFLER, Karl. Ernesto de Fiori. In: Kunst und Künstler, XVIII. Berlim, 1920, p. 484.

SIEMSEN, Hans. Ernesto de Fiori. In: Deutsche Kunst und Dekoration, Darmstadt, n. 64 , p. 243 e ss., jul. 1929.

Walter Zanini é professor de História da Arte da Escola de Comunicações e Artes da USP e professor visitante do Collège de France. 


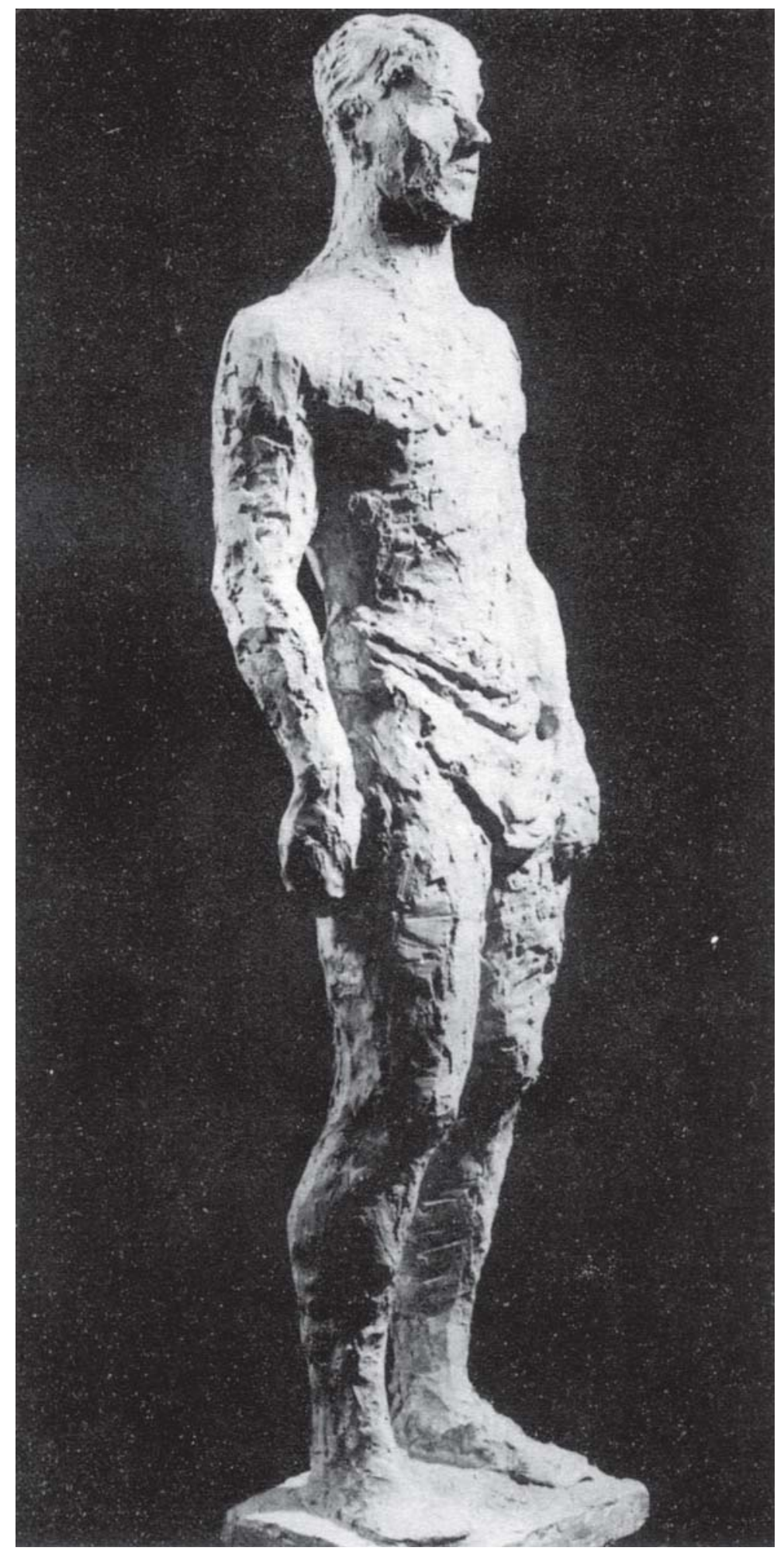

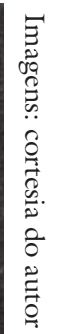

O Brasileiro, 1938.

Gesso, c/base.

Col. Museu de Arte

Contemporânea da USP. 


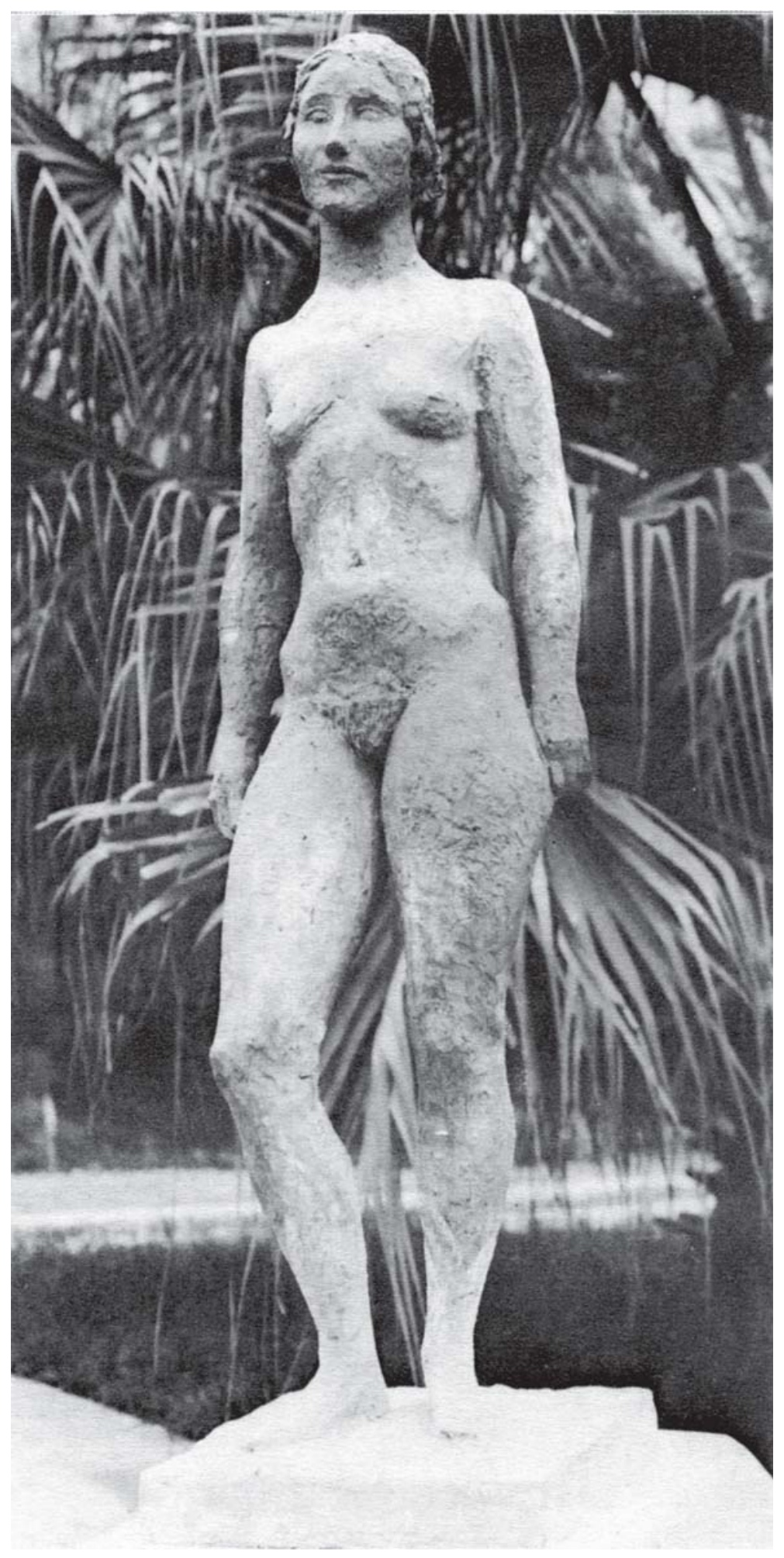

Figura Feminina, 1937. Terracota.

Col. Ornella H. Psillakis. 


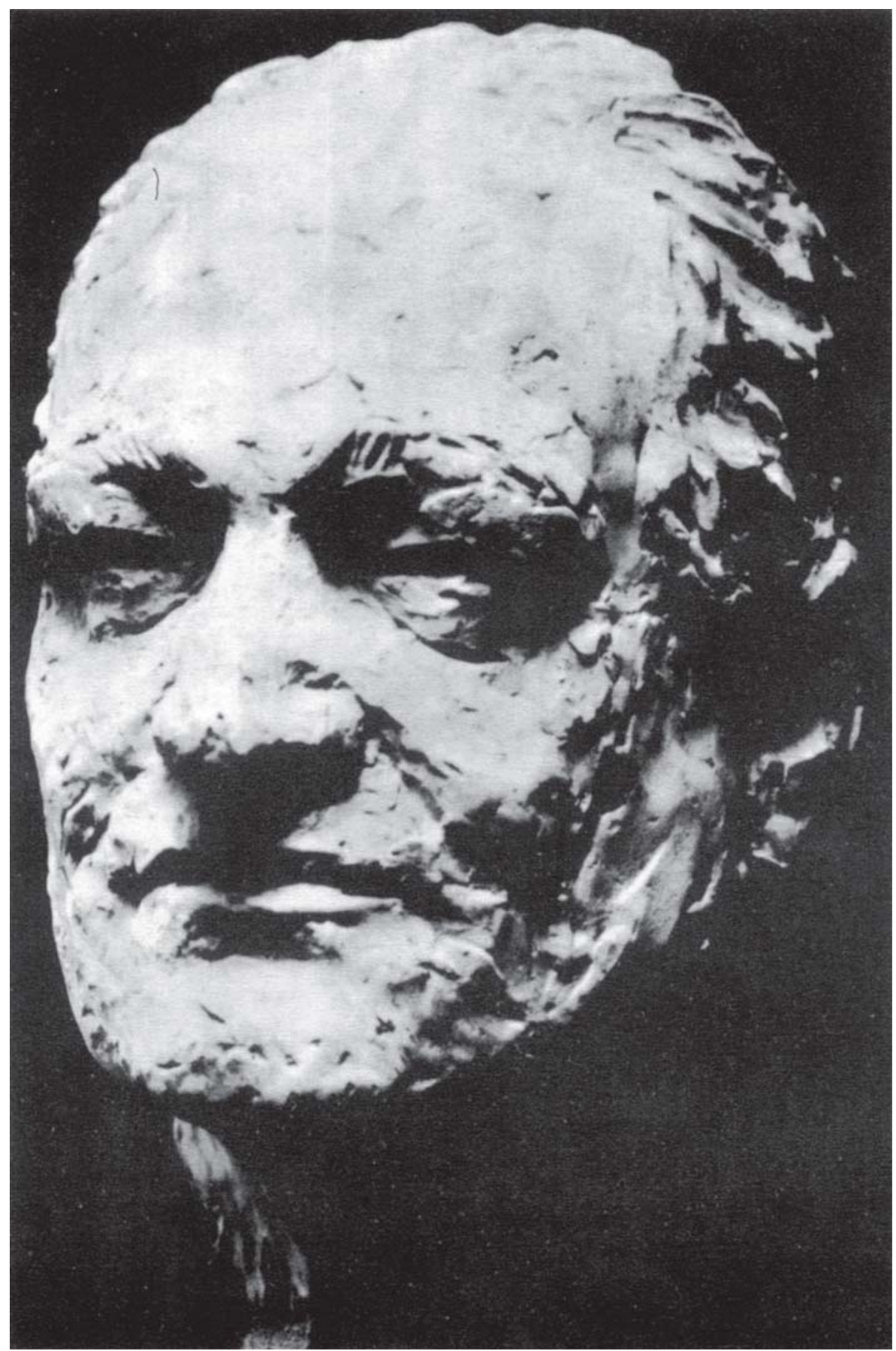

Retrato de Ungaretti, 1936. Gesso. Galleria Nazzionale d'Arte Moderna, Roma. 


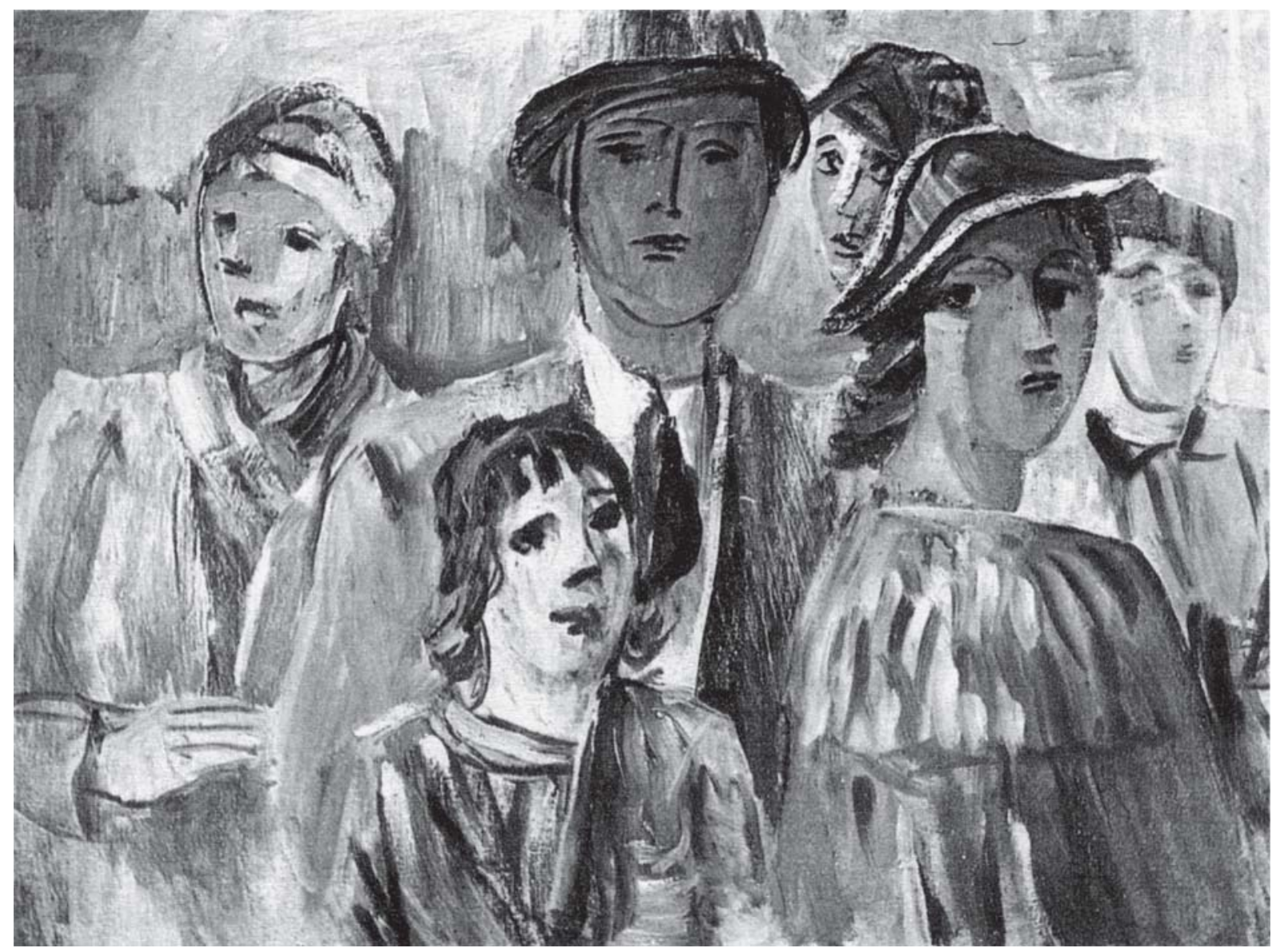

Composição com 6 Figuras, 1943. Óleo s/tela. Col. Ernesto Wolf. 


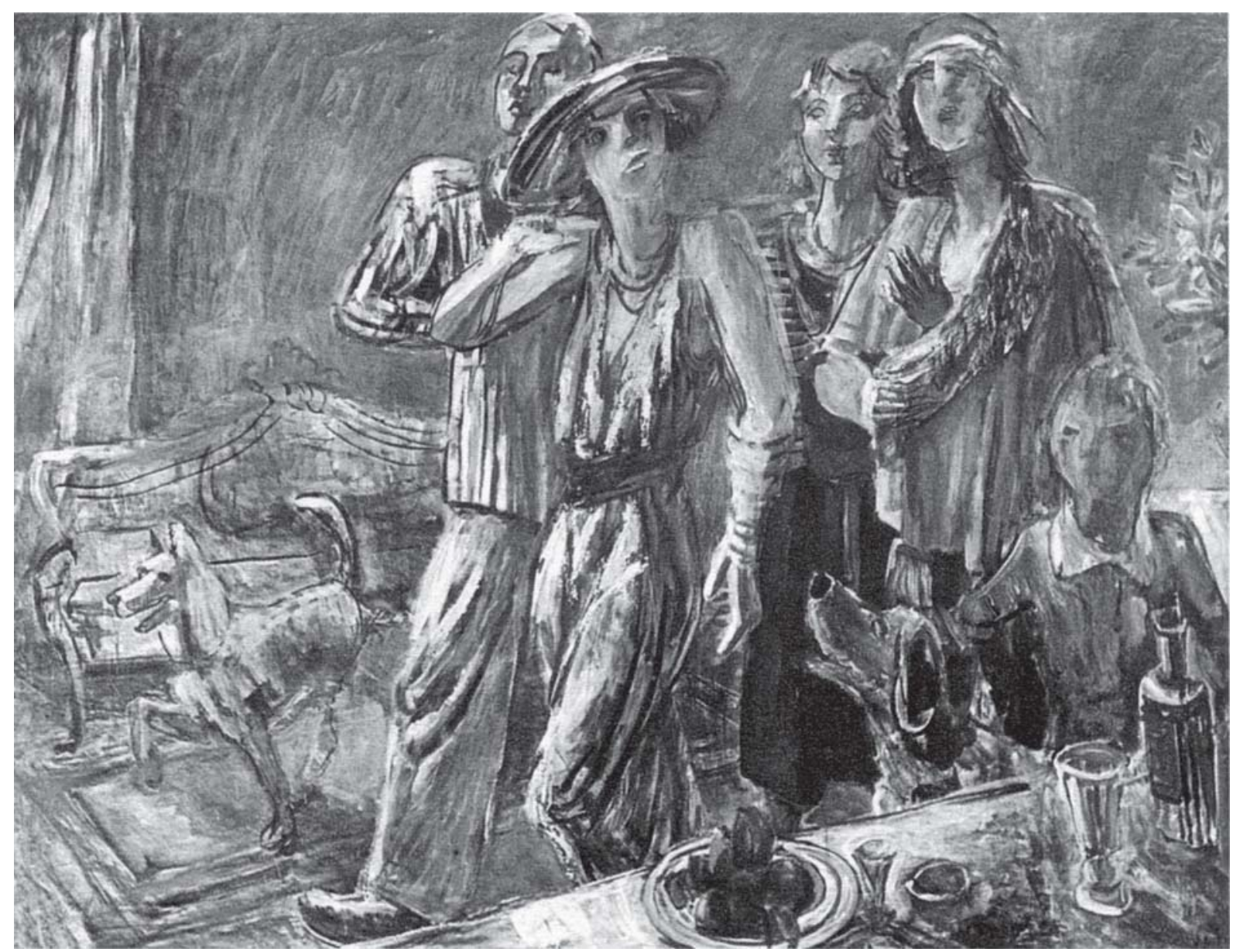

Os Visitantes, 1943. Óleo s/tela. Col. Ornella H. Psillakis. 


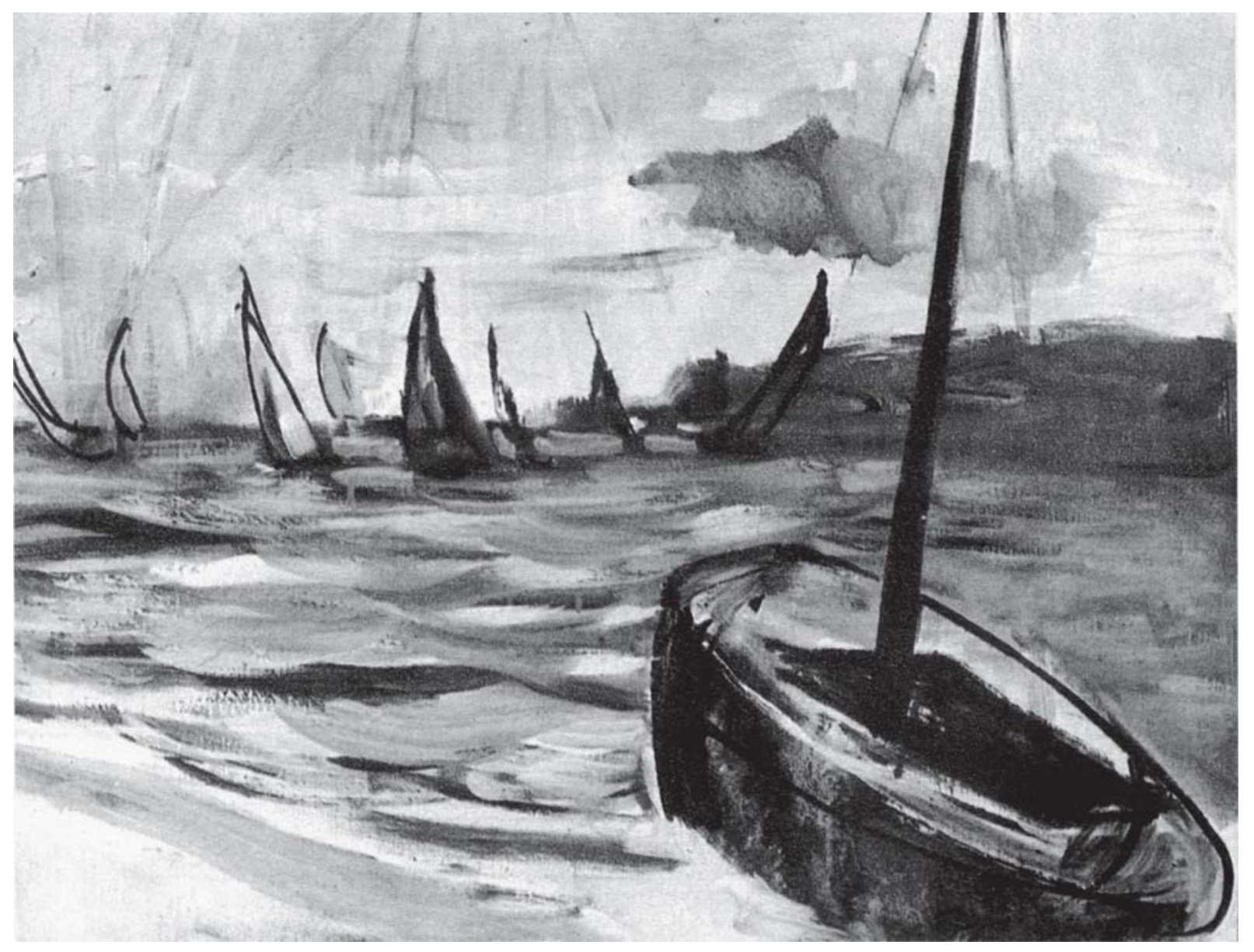

Regata em Santo Amaro, c.1943. Óleo s/tela. Col. Cosme Velho Galeria de Artes. 


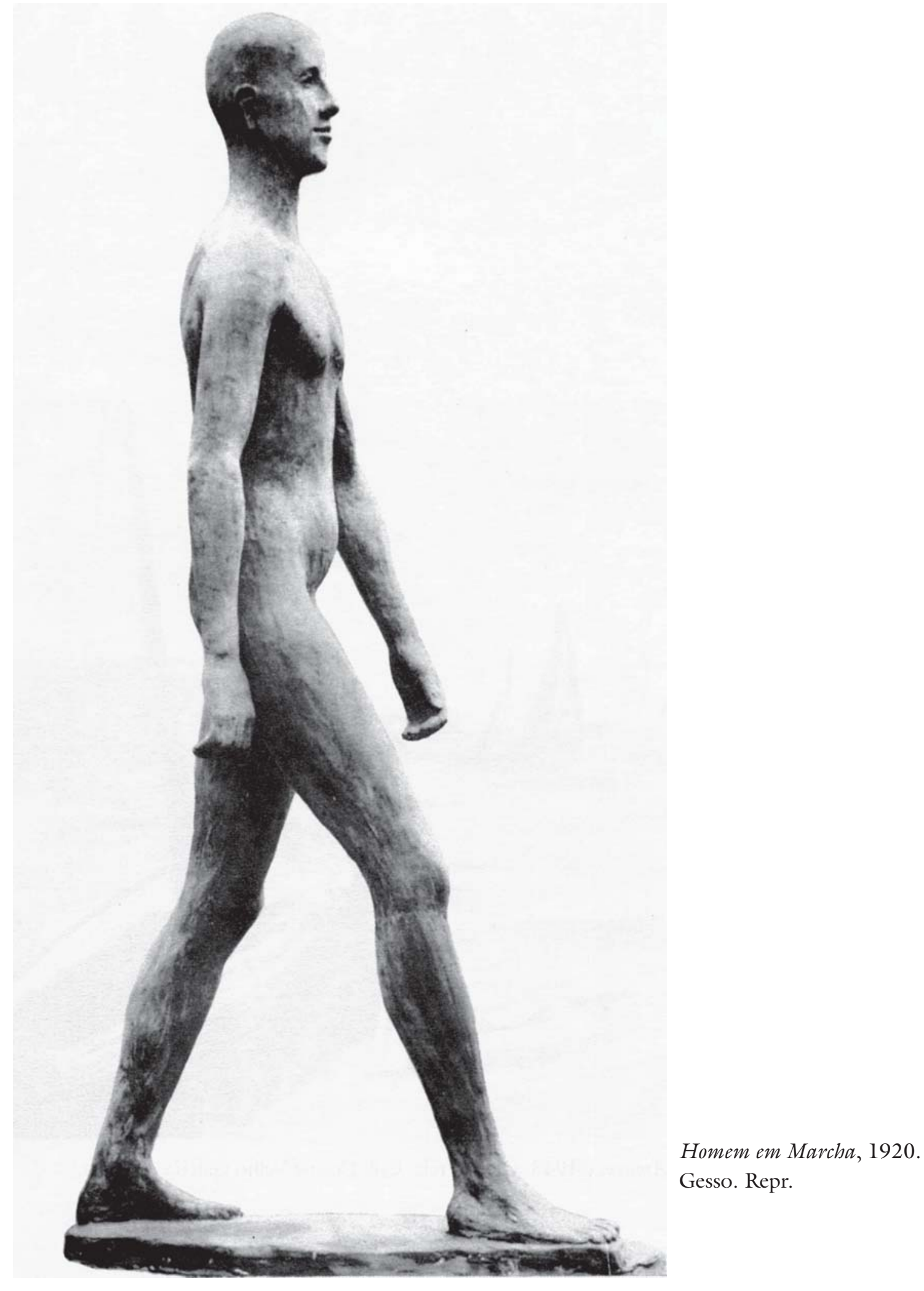




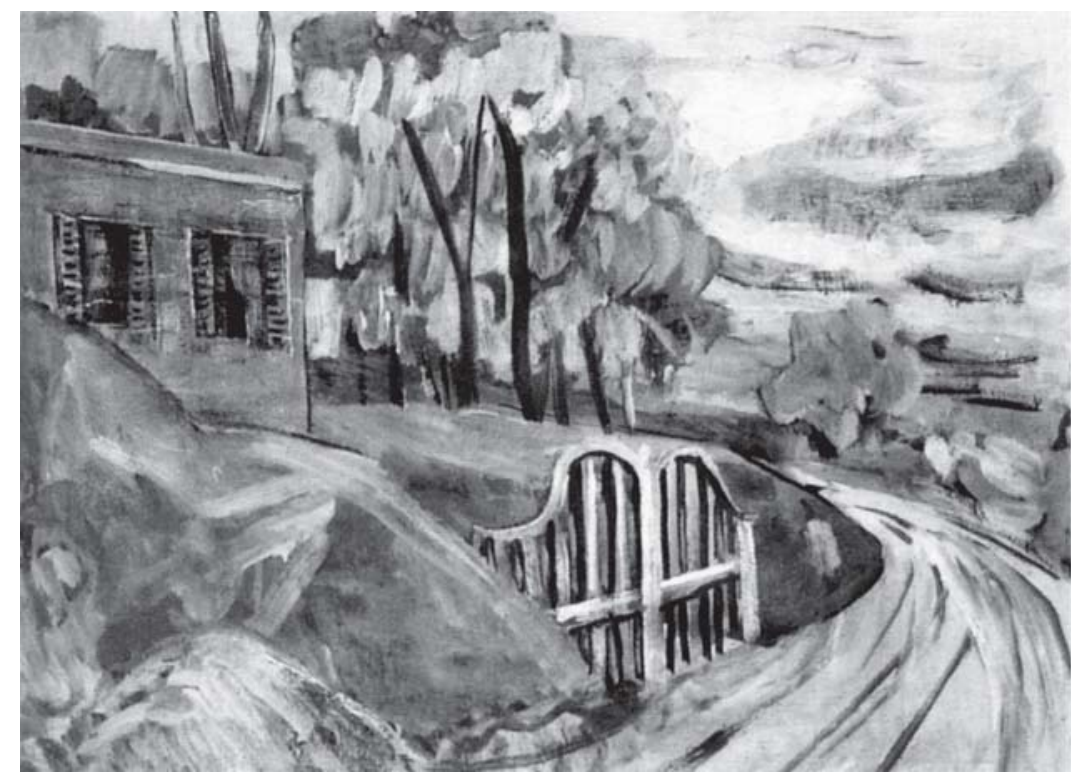

O Portão Branco, 1938. Óleo s/tela. Acervo Banco Itaú, São Paulo.

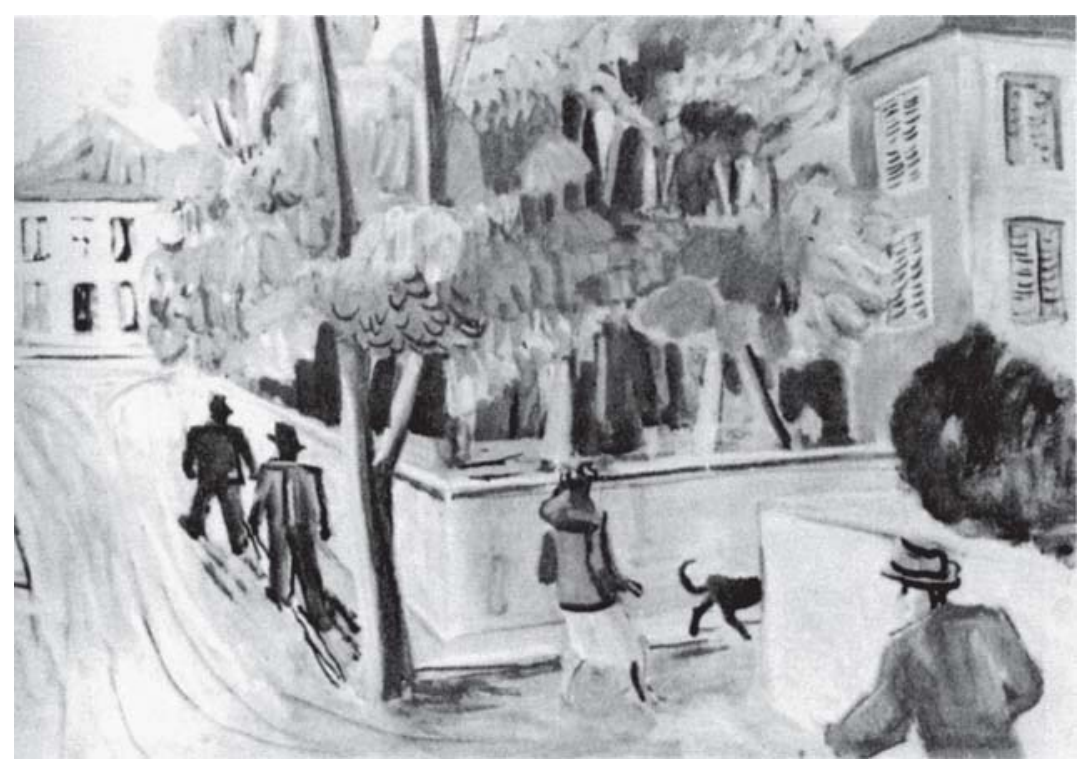

Rua, c.1942. Óleo s/tela. Col. Sérgio De Fiori. 

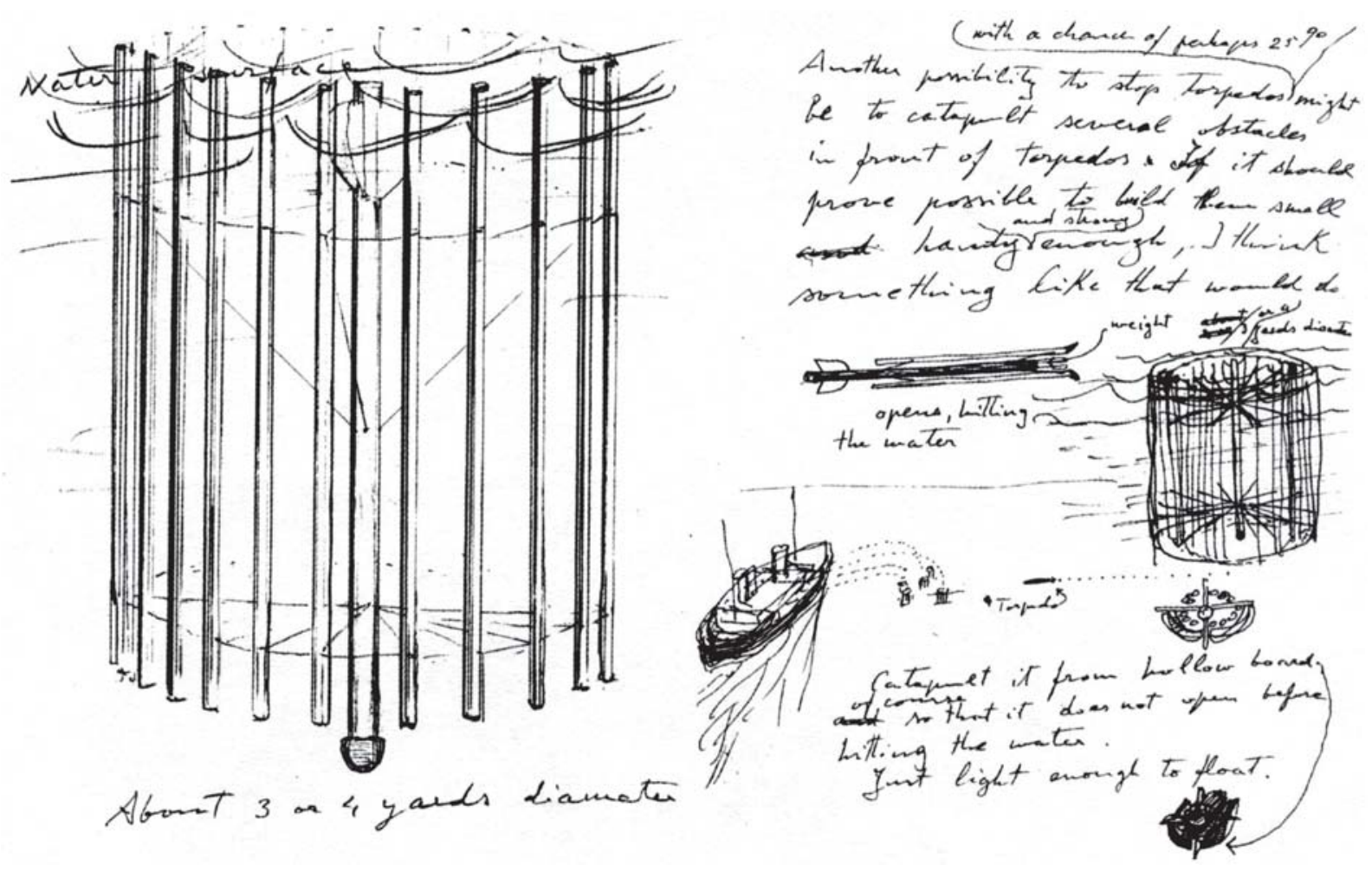

Textos e desenhos de seus torpedonets. 


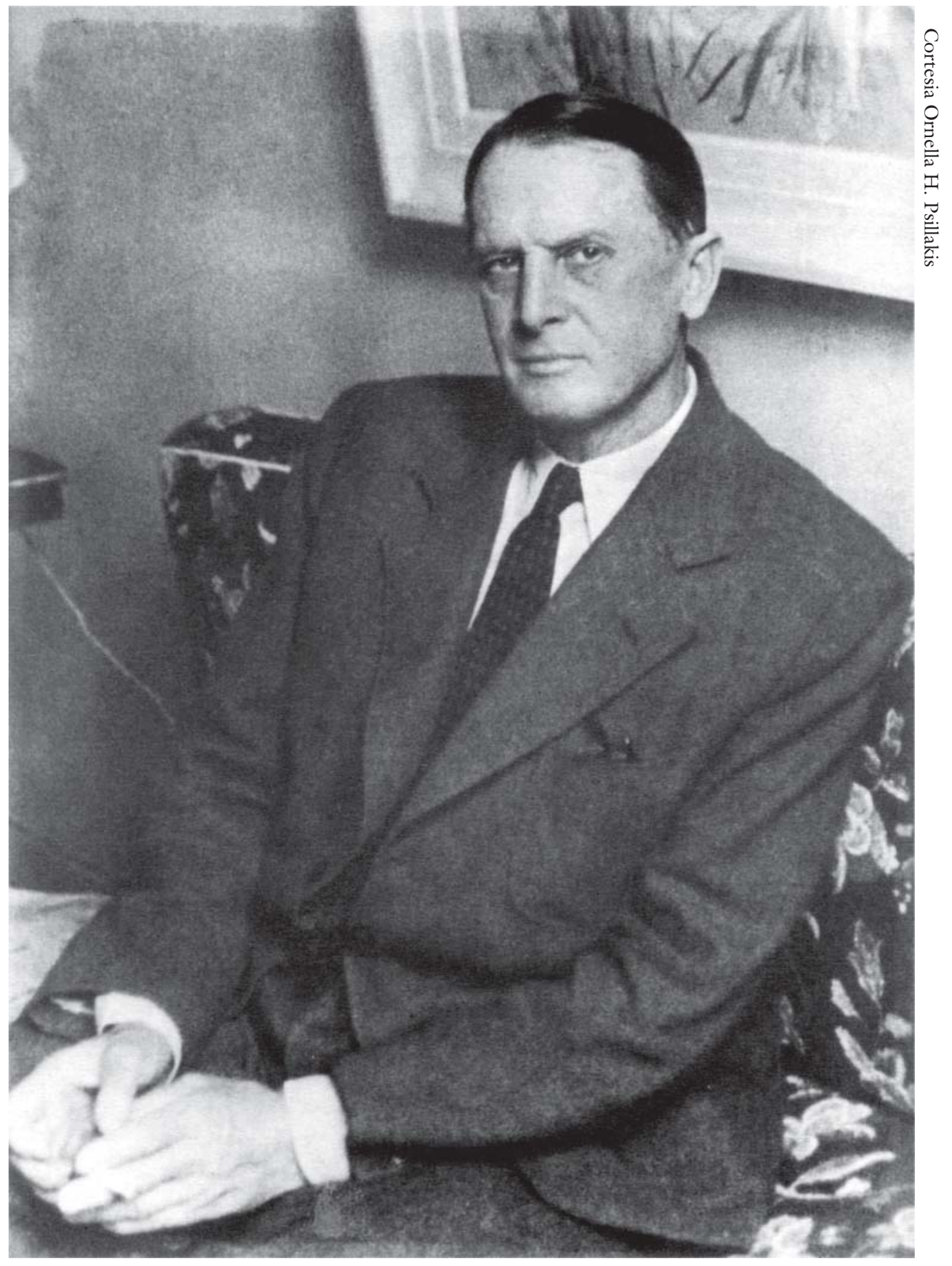

O artista Ernesto De Fiori (1884-1945) 